\title{
MENSTRUAL PROBLEMS AND HEALTH AWARENESS OF TRIBAL ADOLESCENT SCHOOL GIRLS OF ODISHA- A CROSS-SECTIONAL STUDY
}

\author{
Pramila Jena ${ }^{1}$, Narahari Agasti2, Shana Andalib3 ${ }^{3}$,Karan Khandelwal ${ }^{4}$
}

${ }^{1}$ Associate Professor, Department of Obstetrics and Gynaecology, Kalinga Institute of Medical Science and Pradyumna Bal Memorial Hospital, Patia, Bhubaneswar, Odisha.

${ }^{2}$ Associate Professor, Department of Obstetrics and Gynaecology, Kalinga Institute of Medical Science and Pradyumna Bal Memorial Hospital, Patia, Bhubaneswar, Odisha.

${ }^{3}$ Student, Department of Obstetrics and Gynaecology, Kalinga Institute of Medical Science and Pradyumna Bal Memorial Hospital, Patia, Bhubaneswar, Odisha.

${ }^{4}$ Student, Department of Obstetrics and Gynaecology, Kalinga Institute of Medical Science and Pradyumna Bal Memorial Hospital, Patia, Bhubaneswar, Odisha.

\section{ABSTRACT}

\section{BACKGROUND}

Some type of menstrual dysfunction is common in adolescent girls. Tribal adolescents are more vulnerable due to malnutrition, ignorance, poverty, sociocultural taboos and poor medical attention, which causes significant morbidity.

\section{MATERIALS AND METHODS}

The present study was a descriptive cross-sectional study based on self-administered, structured questionnaire conducted on 300 adolescent school going girls from a tribal residential school at Bhubaneswar, Odisha. They were asked to complete a pre-designed questionnaire anonymously. Information related to age of menarche, menstrual pattern, menstrual complaints, its impact on daily activities, source of information and reason to seek medical advice were noted.

\section{RESULTS}

The mean age of the respondent was 13.62 years in this study. Mean age of menarche was 12.07 years with a range being 10 to 16 years. Majority had regular cycle (76.09\%) with cycle length of 21 to 35 days (96.97\%). The most prevalent menstrual symptom was dysmenorrhoea (52\%). 89.9\% feel that their knowledge regarding reproductive health is inadequate. Only $13.45 \%$ sought advice for their menstrual problems and the source of advice was mostly from friends (66.33\%). 11.7\% received medical treatment. School absenteeism was noted in $9.76 \%$ and restricted sports activities in $44.78 \%$.

\section{CONCLUSION}

Menstrual problems are a significant source of morbidity and major cause of school absenteeism. Many adolescent girls have inadequate information about menstrual problem and are reluctant to seek medical advice, leading to delay in diagnosis and treatment. Appropriate health education measures are required to prevent this trend.

\section{KEYWORDS}

Adolescence, Menarche, Menstrual Pattern, Menstrual Hygiene, Reproductive Health Education, Socioeconomic Class, Tribal Girl.

HOW TO CITE THIS ARTICLE: Jena P, Agasti N, Andalib S, et al. Menstrual problems and health awareness of tribal adolescent school girls of Odisha- A cross-sectional study. J. Evolution Med. Dent. Sci. 2017;6(51):3917-3921, DOI: $10.14260 /$ Jemds/2017/847

\section{BACKGROUND}

The tribal populations constitute a unique population as they live in geographically isolated area under primitive conditions with their typical social and cultural practice. They are at risk of undernutrition because of their agricultural practice, uncertainty of food supply and have limited access to health care facilities. Menarche, the first menstrual period which indicates the maturity of reproductive potential and physiological growth,

Financial or Other, Competing Interest: None.

Submission 21-05-2017, Peer Review 14-06-2017,

Acceptance 20-06-2017, Published 24-06-2017.

Corresponding Author:

Dr. Pramila Jena,

Associate Professor,

Department of Obstetrics and Gynaecology,

Kalinga Institute of Medical Science and

Pradyumna Bal Memorial Hospital,

Campus-5, Patia, Bhubaneswar-24, Odisha.

E-mail: drpramila@hotmail.com

DOI: $10.14260 /$ jemds $/ 2017 / 847$ generally occurs at 10 to 14 years in $95 \%$ of girls depending on race, ethnicity, and socioeconomic and nutritional status. ${ }^{1}$ Irregular menstrual pattern is quite common due to hormonal fluctuation and immaturity of the hypo-thalamopituitary-ovarian axis during adolescent period. This may create diagnostic dilemma for physicians and may result in a delay in the treatment of underlying problems. ${ }^{2}$

Out of various menstrual problems reported in adolescents, dysmenorrhoea is most common and is the frequent cause of school absenteeism and restriction of daily activities. $^{3}$

Although menstrual problems have tremendous impact on adolescent health only very few seek medical advice. Hence, there is underutilisation of health care services by adolescents. 2,3,4,5 Not uncommonly they feel shy to talk about the menstruation and are afraid of seeing doctors. Due to lack of appropriate advice and guidance what they generally get from their peer groups and mother, they undergo silent suffering and acceptance of menstrual problems. 


\section{Aims and Objectives \\ Aim}

To find out occurrence of various menstrual disorders and their health awareness behaviour of adolescent school going girls of tribal Odisha and to find out if they differ significantly from the general population.

\section{Objectives}

To know the

1. Prevalence of various menstrual disorders in the adolescents.

2. Source of knowledge and their approach to menstrual problems.

3. Health awareness behaviour of tribal adolescent girls.

\section{MATERIALS AND METHODS}

This was a descriptive cross-sectional study based on selfadministered, structured questionnaire undertaken from July to September, 2011.

Out of 600 adolescent girls studying in a tribal residential school at Bhubaneswar, Odisha, 300 adolescent school going girls aged 11-19 years who attained menarche were selected by simple random method for the study. The sample size calculated as per the prevalence of severe dysmenorrhoea during menstrual period $37.96 \%$. In the study by 'A study of dysmenorrhoea during menstruation in adolescent girls by Agarwal $\mathrm{AK}$ et al, in the Indian Journal of Community Medicine 2010, Jan:35 (1):159-164, considering the formulae $4 \mathrm{pq} / \mathrm{d}^{2}$, with the desired level of precision $=6 \%$, and also by considering $10 \%$ as non-respondent, the final sample size came to 284 . So we considered here the sample size 300 . Out of them, 3 were excluded from the study as they did not respond to the questionnaire properly.

They were explained about the purpose of the study by the investigator and principal of the school before their voluntary participation was requested. Consent from the principal of the school was obtained. They were asked to fill in the questionnaire. The questionnaire included demographic details, age of menarche, psychological response towards menstruation, current menstrual status, presence of any menstrual problems, its severity, impact on daily activities/school attendance, whether medical attention was received, barrier to seek medical services, source of their knowledge and information, etc.

Menstrual pattern of the subjects is considered regular if cycle length is 21-35 days with a mean of $28 \pm 2$ days and irregular when it will be less than 21 days or more than 35 days. Menstrual flow was considered as scant, average and heavy one based on number of sanitary towels used (1-2, 3-5 and $>5$ sanitary towel per day as scanty, average and heavy menstrual flow respectively). Common definitions used to collect data are Amenorrhoea (Primary): absence of menarche till the age of 16 years. Amenorrhoea (Secondary): no menses for three months or more, oligomenorrhoea or infrequent menses (menstrual cycles of 35-90 days). Menorrhagia: excessive bleeding $>500 \mathrm{~mL} /$ soaked pads $>5 /$ day/ periods lasting $>7$ days. Metrorrhagia: breakthrough bleeding or spotting in-between periods. Hypomenorrhoea (Scanty bleed): regularly timed but scanty bleeding ( $<50 \mathrm{~mL} /$ soaked pads 1-2/day), Dysmenorrhoea: lower abdominal pain accompanying the menstrual cycle. Premenstrual syndrome: symptoms like abdominal pain, leg cramps, headache, low backache, breast tenderness, irritability, etc. before onset of menstruation. ${ }^{6-9}$

All data entered in MS Excel were analysed using percentages and proportions.

\section{RESULTS}

Response rate $99 \%, 1 \%$ did not fill in the questionnaire properly thus excluded from the study. The mean age of the respondent 13.62 years. The age range 11.4-18.3 years.

\begin{tabular}{|c|c|c|}
\hline Age & No. & Percentage \\
\hline & 7 & 2.36 \\
\hline 10 to 11 & 68 & 22.89 \\
\hline 11 to 12 & 202 & 68.01 \\
\hline 12 to 13 & 17 & 5.72 \\
\hline 13 to 14 & 2 & 0.67 \\
\hline 14 to 15 & 1 & 0.34 \\
\hline 15 to 16 & 0 & 0 \\
\hline 16 to 17 & Table 1. Age at Menarche \\
\hline \multicolumn{3}{|c|}{} \\
\hline
\end{tabular}

Median age of menarche is 12.7 years.

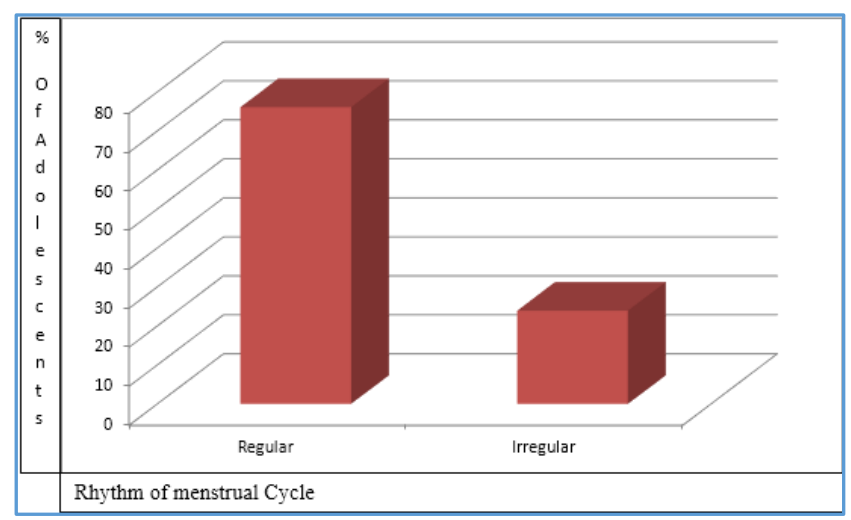

Figure 1. Rhythm of Menstrual Flow

The rhythm is regular in majority.

\begin{tabular}{|c|c|c|}
\hline \multicolumn{3}{|c|}{ Cycle Length } \\
\hline & No. $(n=297)$ & Percentage \\
\hline$<21$ & 6 & 2.02 \\
\hline $21-35$ & 288 & 96.97 \\
\hline$>35$ & 3 & 1.01 \\
\hline \multicolumn{3}{|c|}{ Duration of Bleeding } \\
\hline$<=2$ Days & 5 & 1.7 \\
\hline 3-5 Days & 223 & 75.1 \\
\hline 5-7 Days & 53 & 17.8 \\
\hline Others & 10 & 3.39 \\
\hline Not responded & 6 & 2.01 \\
\hline \multicolumn{3}{|c|}{ No. of Pads used } \\
\hline $\begin{array}{c}1-2 \text { (scanty } \\
\text { bleeding) }\end{array}$ & 207 & 69.69 \\
\hline $\begin{array}{c}\text { 3-5 (average } \\
\text { bleeding) }\end{array}$ & 69 & 23.23 \\
\hline$>5$ (heavy bleeding) & 12 & 4.04 \\
\hline Not responded & 9 & 3.04 \\
\hline \multicolumn{3}{|c|}{ History of Passing Clots } \\
\hline Yes & 95 & 31.99 \\
\hline No & 202 & 68.01 \\
\hline \multicolumn{3}{|c|}{ No. of Girls Knowing their LMP } \\
\hline Yes & 59 & 19.9 \\
\hline No & 238 & 80.1 \\
\hline \multicolumn{3}{|c|}{ Table 2. Menstrual Profile } \\
\hline
\end{tabular}




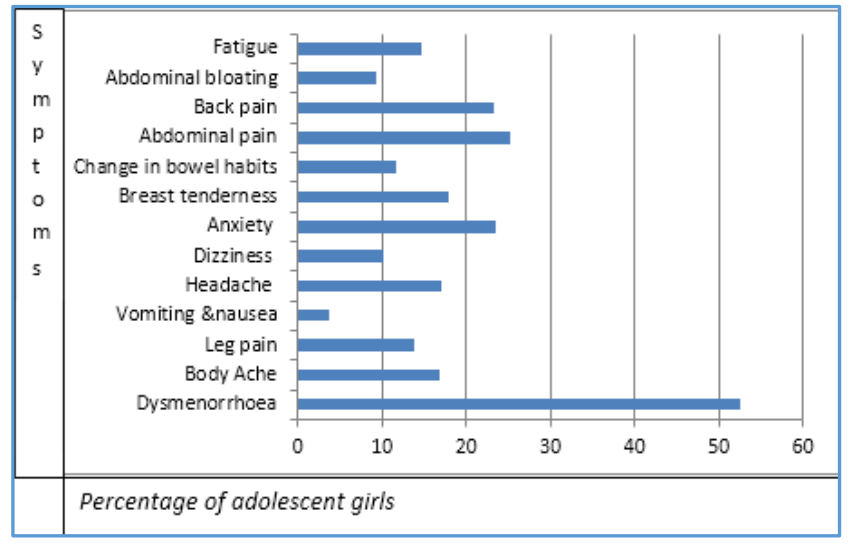

Figure 2. Associated Symptoms

\begin{tabular}{|c|c|c|}
\hline Activities Restricted & No. $(n=297)$ & Percentage \\
\hline Daily activities & 59 & 19.87 \\
\hline Sports activity & 133 & 44.78 \\
\hline Outdoor activities & 68 & 22.9 \\
\hline School absenteeism & 29 & 9.76 \\
\hline No impact & 8 & 2.7 \\
\hline \multicolumn{3}{|c|}{$\begin{array}{c}\text { Table 3. Impact of Menstruation and Menstrual Problems } \\
\text { on Various Activities }\end{array}$} \\
\hline
\end{tabular}

\begin{tabular}{|c|c|c|}
\hline \multicolumn{3}{|c|}{ Sought for Advice } \\
\hline Sought for advice & No. (n=297) & Percentage \\
\hline Yes & 40 & 13.45 \\
\hline No & 257 & 86.55 \\
\hline \multicolumn{3}{|c|}{ From whom } \\
\hline Family & 0 & 0 \\
\hline Friend & 197 & 66.33 \\
\hline Doctor & 25 & 8.42 \\
\hline Nurse & 75 & 25.25 \\
\hline Midwife & 0 & 0 \\
\hline Received any Medical Treatment \\
\hline Yes & 35 & 11.7 \\
\hline No & 262 & 88.3 \\
\hline \multicolumn{2}{|c|}{ Responded to the Treatment } \\
\hline Yes & 35 & 100 \\
\hline No & 0 & 0 \\
\hline
\end{tabular}

Factors Influencing her Decision to seek Medical Advice

\begin{tabular}{|c|c|c|}
\hline Severity of symptoms & 200 & 76.34 \\
\hline $\begin{array}{c}\text { Opinion of family } \\
\text { members }\end{array}$ & 5 & 1.91 \\
\hline Doctor's gender & 30 & 11.45 \\
\hline $\begin{array}{c}\text { Anxiety about facing } \\
\text { embarrassing } \\
\text { questioning }\end{array}$ & 20 & 7.63 \\
\hline Cost of consultation & 2 & 0.76 \\
\hline Time constraints & 5 & 1.91 \\
\hline
\end{tabular}

Table 4. Health Awareness Behaviour

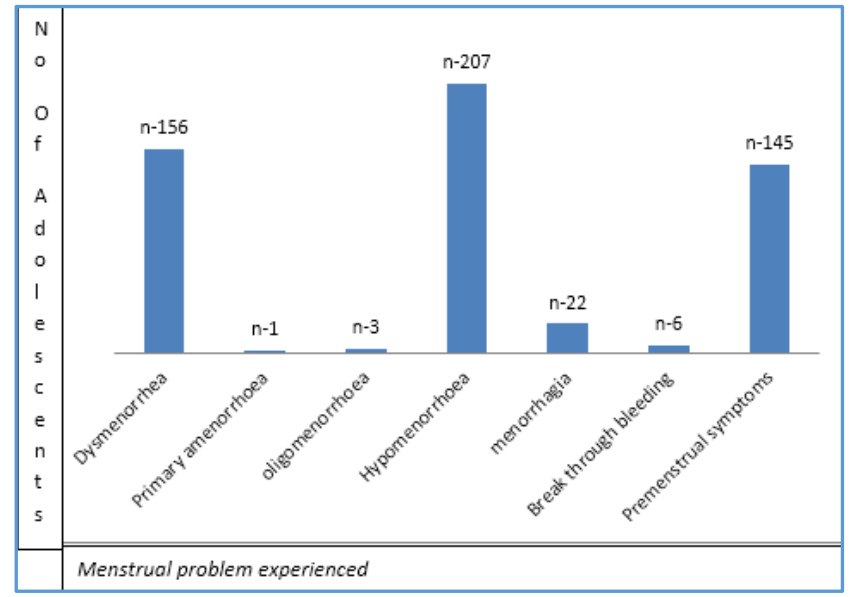

Figure 3 -Various Menstrual Problem Experienced

\begin{tabular}{|c|c|c|}
\hline \multicolumn{3}{|c|}{ Source of Knowledge } \\
\hline & No. $(n=297)$ & Percentage \\
\hline Mother & 106 & 35.69 \\
\hline Friends & 10 & 3.39 \\
\hline $\begin{array}{l}\text { Other family } \\
\text { members }\end{array}$ & 8 & 2.69 \\
\hline School education & 173 & 58.23 \\
\hline \multicolumn{3}{|c|}{ Girls Considering their Knowledge Adequate } \\
\hline Yes & 30 & 10.1 \\
\hline No & 267 & 89.9 \\
\hline \multicolumn{3}{|c|}{ Girls Accepting Menstruation as Normal } \\
\hline Yes & 142 & 47.8 \\
\hline No & 155 & 52.2 \\
\hline \multicolumn{3}{|c|}{ Different Psychological Response } \\
\hline Excitement & 17 & 10.97 \\
\hline Confusion & 29 & 18.97 \\
\hline Sadness & 27 & 17.41 \\
\hline Rejection & 12 & 7.74 \\
\hline Apprehension & 13 & 8.39 \\
\hline Fear & 40 & 25.81 \\
\hline Disgusting, Messy & 17 & 10.97 \\
\hline \multicolumn{3}{|c|}{ Duration of the Psychological Response (in months) } \\
\hline 1 to 3 & 88 & 56.77 \\
\hline 3 to 6 & 36 & 23.23 \\
\hline 6 to 12 & 23 & 14.84 \\
\hline$>12$ & 8 & 5.16 \\
\hline \multicolumn{3}{|c|}{$\begin{array}{c}\text { Percentage of Girls finding Questions about } \\
\text { Menstruation, Pregnancy, Contraception and STDs } \\
\text { Embarrassing }\end{array}$} \\
\hline Yes & 62 & 20.9 \\
\hline No & 235 & 79.1 \\
\hline \multicolumn{3}{|c|}{ Percentage of Girls having Information Regarding STDs } \\
\hline Yes & 30 & 10.1 \\
\hline No & 264 & 88.89 \\
\hline Not willing to answer & 3 & 1.01 \\
\hline
\end{tabular}

\section{DISCUSSION}

In the present study, the mean age of the respondents was 13.62 respectively. Mean age of menarche is 12.7 years. This corresponds to the mean age of menarche quoted in various 
studies done by Peacock et al, 5 Shahbazian et al, ${ }^{10}$ and Singh et al, ${ }^{11}$ Shipra Nagar. ${ }^{12}$

The regular rhythm of the menstruation cycle in this study was $76.09 \%$. Irregular cycles were reported in $23.91 \%$. Similar findings were also reported by Agarwal et $\mathrm{al}^{2}$ and Verma et el ${ }^{13}$ and Begum et al. ${ }^{1}$

Majority of girls could not recall their LMP. 97\% reported menstrual cycle of length 21 to 35 days similar to study of Chan et $\mathrm{al}^{3}$ where $60-80 \%$ cycles were 21 to 35 days. The duration of the flow was 3 to 5 days in $75.1 \%$. Average flow was reported in $23.33 \%$ whereas scanty bleeding in $69.69 \%$. Majority of tribal girls reporting scanty bleeding which is in contrast to Chan et al study ${ }^{3}$ might be due to malnutrition and iron deficiency anaemia. In our study, 3.04\% girls have poor understanding of menstruation as they did not respond to these specific questions.

In contrast to other study such as Nwankwo et $\mathrm{al}^{14}$ where associated symptoms were quoted as high as $69.4 \%$, our study revealed only $31.97 \%$ had associated symptoms. Significant number of tribal girls remaining symptom free in menstrual period might be due to lack of health awareness and ignorance which made them to accept symptoms and develop more tolerance.

The major symptoms were dysmenorrhoea in 52\% which was less than what was reported in J Begum study, where the prevalence of dysmenorrhoea was $60.9 \% .^{1}$ Family history of dysmenorrhoea was reported in $32 \%$ which was similar to J Begum et al study. ${ }^{1}$

Not uncommonly menstrual problems are a source of significant debility in adolescent girls. In our study, almost one fourth of girls had restriction of daily activity and approximately one half had restricted sports activity during menstruation. School absenteeism reported in our study were significantly lower $(9.76 \%)$ in contrast to several other studies. However, dysmenorrhoea was the major cause for school absenteeism (52.53\%).1-4,10,11,13,15-18.

For their problems, very few $(13.45 \%)$ took advice. Out of them only $8 \%$ went to doctors, this is more or less similar to the findings of study conducted by Nwankwo et al ${ }^{14}$ and Chan et al. ${ }^{3}$

$11 \%$ needed treatment and the response rate was very good $(100 \%)$. The tribal girls have better tolerance for their menstrual symptoms, therefore needing less medical attention and higher satisfaction rate. The main reason for seeking medical advice was the severity of symptoms.

In our study, many girls feel shy to talk about menstruation and were afraid of gynaecological examination. Not uncommonly many girls feel uncomfortable to take advice from a male doctor. (Chan et al, 2009). ${ }^{3}$

Despite the significant impact on health, only a small proportion of girls in our study obtained medical attention although staying in a residential school where they have access to health care facilities. Underutilisation of health care system and low consultation rate by adolescents has also been reported in many studies, ${ }^{2-5}$ and we do not know exactly how worse the situation in their native dwelling place is.

$89 \%$ of adolescent girls are not satisfied by their current knowledge about menstruation and reproductive health. Around half of the adolescent girls did not accept menarche and menstruation normally in the present study. They have variable psychological response to menarche and menstruation. It is messy and disgusting to some, whereas unknown fear complex dominates many others. Shanbhag study ${ }^{19}$ at Bangalore city also revealed similar psychological response such as fear (44.1\%), anxiety in $26.1 \%$. This could be due to lack of prior knowledge. However, this psychological response was more at the start of menses lasting for few months and gradually decreased with time. $49 \%$ felt embarrassed when asked questions about menstruation, pregnancy, contraception and STDs. 88\% of them did not have any information regarding STDs and contraception, $9 \%$ of adolescent girls were not willing to answer about STDs and contraception.

\section{CONCLUSION}

The majority of menstrual disorders are usually self-limiting as most are due to the immaturity of the hypothalamicpituitary axis, but some are attributable to significant pathology. Menstrual problems are a significant source of morbidity in adolescents. The major cause of suffering in adolescent girls is lack of knowledge and insufficient information about menstrual problems in unprivileged tribal sector. Moreover, reluctance to seek medical treatment may aid to further suffering due to delay in diagnosis and treatment.

Health education measures, revising school curriculum to include related topics is helpful to break the barrier. Involving and educating their mothers who are primarily responsible for the transmission of such type of information should be highly encouraged.

\section{ACKNOWLEDGEMENTS}

We thank Indian Council of Medical Research (ICMR), STS2011 for supporting this part of research work.

\section{REFERENCES-}

[1] Begum J, Hossain AM, Nazneen SA. Menstrual pattern and common menstrual disorders among students in Dinajpur medical college. Dinajpur Med Col J 2009;2(2):37-43.

[2] Agarwal A, Venkat A. Questionnaire study on menstrual disorders in adolescent girls in Singapore. Pediatric Adolesc Gynecol 2009;22(6):365-71.

[3] Chan SS, Yiu KW, Yuen PM, et al. Menstrual problems and health-seeking behaviour in Hong Kong Chinese girls. Hong Kong Med J 2009;15(1):18-23.

[4] Nair MKC, Chacko DS, Darwin MR, et al. Menstrual disorders and menstrual hygiene practices in higher secondary school girls. Indian Journal of Pediatrics 2012;79(1):74-8.

[5] Peacock A, Alvi NS, Mushtaq T. Period problems: disorders of menstruation in adolescents. Arch Dis child 2012;97(6):554-60.

[6] Dutta DC. Textbook of obstetrics. 20 th edn. Central Book House publisher 2010:P 69.

[7] Howkins, Bourne. Shaw's text book of gynecology. 12 $2^{\text {th }}$ edn. Elsevier India Private Ltd 2004:P 226.

[8] Glueck CJ, Morrison JA, Daniels S, et al. Sex hormonebinding globulin, oligomenorrhea, polycystic ovary syndrome, and childhood insulin at age 14 years predict metabolic syndrome and class III obesity at age 24 years. J Pediatr 2011;159(2):308-13. 
[9] Harlow SD, Campbell OMR. Epidemiology of menstrual disorders in developing countries: a systematic review. BJOG: an International Journal of Obstetrics and Gynaecology 2004;111(1):6-16.

[10] Shahbazian N, Falahat F. Prevalence of menstrual disorders in early puberty. Scientific Medical Journal Summer 2007;6(53):181-6.

[11] Singh A, Kiran D, Singh $\mathrm{H}$, et al. Prevalence and severity of dysmenorrhea: a problem related to menstruation, among first and second year female medical students. Indian J Physiol Pharmacol 2008;52(4):389-97.

[12] Nagar S, Aimol KR. Knowledge of adolescent girls regarding menstruation in tribal areas of Meghalaya. Stud Tribes Tribals 2010;8(1):27-30.

[13] Verma PB, Pandya CM, Ramanuj VA, et al. Menstrual pattern of adolescent school girls of Bhavnagar (Gujarat). NJIRM 2011;2(1):38-40.

[14] Nwankwo TO, Aniebue UU, Aniebue PN. Menstrual disorders in adolescent school girls in Enugu, Nigeria. J Pediatric Adolesc Gynecol 2010;23(6):358-63.
[15] Avasarala AK, Panchangam S. Dysmenorrhoea in different settings: are the rural and urban adolescent girls perceiving and managing the dysmenorrhoea problem differently? Indian J community Med 2008;33(4):246-9.

[16] Deo DS, Ghattargi CH. Menstrual problems in adolescent school girls: a comparative study in urban and rural area. India J Prev Sco Med 2007;381:2.

[17] Juha T, Rimpela M. Menstrual pain, health and behaviour in girls. Social Science \& Medicine 1989;29(2):163-9.

[18] Sharma A, Taneja DK, Sharma P, et al. Problems related to menstruation and their effect on daily routine of students of a medical college in Delhi, India. Asia Pac J Public Health 2008;20(3):234-41.

[19] Shanbhag D, Shilpa R, D'Souza N, et al. Perceptions regarding menstruation and practices during menstrual cycles among high school going adolescent girls in resource limited settings around Bangalore city, Karnataka, India. International Journal of Collaborative Research on Internal Medicine \& Public Health 2012;4(7):1353-62. 